\title{
Attributes of cut-off low induced rainfall over the Eastern Cape Province of South Africa
}

S Molekwa

Agricultural Research Council - Institute for Soil, Climate and Water

Pretoria

South Africa

molekwas@arc.agric.za

Tel: +27123102629

Fax: +27123231157

CJ Engelbrecht

Agricultural Research Council - Institute for Soil, Climate and Water

Pretoria

South Africa

CJ de W Rautenbach

Department of Geography, GeoInformatics and Meteorology

Faculty of Natural and Agricultural Sciences

University of Pretoria

Pretoria

South Africa

Concise title

Cut-off low rainfall over the Eastern Cape Province, South Africa

\section{Abstract}

Cut-off low (COL) weather systems that are associated with rainfall over the Eastern Cape are considered in this study. COLs are objectively identified and tracked over a 31-year period. Daily rainfall data of 22 evenly distributed stations over the Eastern Cape are utilized. Only COLs with a minimum spatial distribution, defined as more than a third of the rainfall stations that need to report rainfall on at least one day of a COL event, are considered for analysis of rainfall attributes. These attributes include the occurrence of COL rain days of different magnitudes, the distribution of the depth and temperature of the COL centres for the rain days of different magnitudes, the associated spatial distribution of rainfall as well as the associated atmospheric circulation. The frequency of COLs over the Eastern Cape has a winter maximum and a summer minimum. COL rain days of small, medium and large magnitudes occur most frequently during the winter, while small and medium magnitude COL rain days experience peaks in autumn and spring respectively. The low-level flow, and in particular the position of the low/trough, seems to be the determinant factor in the occurrence, magnitude and spatial extent of COL induced rainfall.

\section{INTRODUCTION}

Cut-off lows (COLs) are amongst the most important synoptic-scale rain producing weather systems in South Africa (Taljaard 1985; Mason and Jury 1997; Singleton and Reason 2007; Favre et al. 2012) and contribute significantly to rainfall over South Africa (Favre et al. 2011). COLs are usually associated with widespread rainfall (Taljaard 1985; Favre et al. 2012), while about 20\% of systems over South Africa are associated with heavy falls of rain (Taljaard 1985). Rainfall associated with COLs that do not induce heavy falls of rain exhibit similar rainfall characteristics with regard to the spatial distribution and amount of rainfall as rainfall associated with westerly wave troughs (Taljaard 1985). Apart from tropical systems that are responsible for major rain events over the summer rainfall region of South Africa (e.g. Dyson and van Heerden 2002; Malherbe et al. 2012), other extreme precipitation events are associated with COLs (e.g. Estie 1981; Taljaard 1985; Singleton and Reason 2006; Muller et al. 2008). In such extreme events, the daily rainfall associated with a COL can be more than three times the long-term monthly mean. It seems that these extreme events over South Africa have no preferential 
geographical or seasonal occurrence. It often happens that an extreme rainfall day over South Africa outside of the rainy season can be attributed to a COL (Favre et al. 2012). Further, COLs are most of the time responsible for rain during winter over the summer rainfall area of South Africa (Taljaard 1995; Favre et al. 2012) - early onset of summer rainfall is often associated with COLs (Tennant and Reason 2005), with potential implications on agricultural practices.

COLs are cold-cored closed cyclones in the middle and upper troposphere that develop in the westerlies, equatorwards of the polar jetstream (Taljaard 1985; Keable et al. 2002; Favre et al. 2012). COLs can be accompanied by intense thunderstorms due to instability as a result of the cold pool associated with the COL centre (Singleton and Reason 2006; Favre et al. 2012). It is also possible that the middle and upper tropospheric low extends to the surface in which case it is usually associated with widespread heavy precipitation (Taljaard 1985; Favre et al. 2012), in particular along the south and southeastern coastal belt and adjacent interior of South Africa as the surface low exits the land (Taljaard 1985), enhancing the strength of an onshore low-level jet onto the coastal mountains (Singleton and Reason 2006). Heavy rain typically occurs when the system is still baroclinic and when a surface low is present some hundreds of kilometres east of the upper low (Taljaard 1995). COLs are weather systems with a high potential of good rainfall over an extensive area (Taljaard 1985) as these systems are usually slow moving (Favre et al. 2012) due to the presence of a blocking high (Keable et al. 2002) on occasions. It is such a system that contributed to the extensive rainfall during the February 1988 floods (Lindesay and Jury 1991). COLs usually move according to the general mean atmospheric flow - that is in an easterly direction south of $30^{\circ} \mathrm{S}$ and in a westerly direction in the tropics (Favre et al. 2012). Even so, the movement of COLs can be erratic, more so for the COLs located at lower latitudes (Favre et al. 2012).

Geographically, there are two favoured areas in the southern African region and surrounding oceans for the occurrence of COLs. Most COLs occur in the southern Mozambique Channel (Keable et al. 2002; Favre et al. 2012; Engelbrecht et al. 2013) while the second maximum is located over the Atlantic Ocean just off the west coast of South Africa (Fig. 1a), with a tongue of lower frequency of occurrences extending in over the southwestern part of the country (Favre et al. 2012; Engelbrecht et al. 2013). Based on data for a 10-year period, 1973-1982, the frequency of COLs that have a lifespan of more than 2 days over and in the immediate vicinity of South Africa is 11 systems per year (Taljaard 1985). The frequency of COLs with a duration of at least 1 day as detected on the $300 \mathrm{hPa}$ heights in the National Center for Environmental Prediction (NCEP) reanalysis data for the period 1973-2002 also yields about 11 systems per year (Singleton and Reason 2007). An annual frequency of about 14 COLs on $500 \mathrm{hPa}$ occurs for the period 1979-2010 (Favre et al. 2012) over the same area as the studies performed by Taljaard (1985) and Singleton and Reason (2007). COLs occur mostly in autumn (March to May) and spring (August to October) in the 10-year dataset (Taljaard 1985), while these systems occur most frequently during March-April-May and to a lesser extent during June-July-August in both the 1973-2002 (Singleton and Reason 2007) and 1979-2010 (Favre et al. 2012) datasets. The contribution of COLs to annual rainfall over South Africa is smaller over the northeastern and 
southwestern parts compared to the remainder of the country. The south and east coast region of South Africa as well as the transition zone between the summer and winter rainfall regions are the areas with the strongest COL contribution to rainfall over South Africa (Favre et al. 2012) - these regions are part of the Eastern Cape, except for the northeastern part of the province. It appears that COLs contribute to the autumn rainfall peak over the Eastern Cape (Jury and Levey 1993). Failure of rain during autumn often leads to conditions of agricultural drought (Jury and Levey 1993).

The good spatial distribution of COL induced rainfall, as well as the occurrence of heavy rainfall associated with COLs, is important to agriculture. Widespread rainfall secures good grazing potential, while heavy rainfall contributes largely to maintaining dam levels. Agriculture in the Eastern Cape Province of South Africa is predominantly rain-fed, hence the importance of COL induced rainfall. However, flood producing COLs can lead to damage to infrastructure and regional agriculture and even loss of life (Weldon and Reason 2013). Although COLs are most frequent over South Africa during autumn (Taljaard 1985; Singleton and Reason 2007; Favre et al. 2012), their contribution to annual rainfall over the country is the highest during October-November-December while the coastal regions receive the highest contribution during July-August-September. In this study, attributes of COLs that lead to rainfall over the Eastern Cape are investigated. Specifically, COL induced rainfall important to agriculture, defined here as rainfall events with a minimum spatial distribution and of various magnitudes, is investigated. The seasonality, geographical location of the COL centres, atmospheric circulation, rainfall distribution as well as some diagnostic characteristics associated with these events are presented.

\section{DATA AND METHODOLOGY}

Twenty-two rainfall stations from the South African Weather Service (SAWS) were identified as having daily data available for the period 1979-2009 and to have a reasonable balanced geographical distribution over the Eastern Cape Province (Fig. 1b). The study period commences in 1979 to be consistent with the availability of reanalysis data from the NCEP where satellite data is employed in the reanalysis procedure (Tennant 2004). Before utilization of the daily rainfall data, it was subjected to an extreme value test as well as a missing data test. The highest 24-hr rainfall during this period occurred at East London on 15 August 2002 when $317.2 \mathrm{~mm}$ was measured. In the event where less than 20 days within a specific month for a station failed the quality control tests, that specific month for the relevant station was not considered in the analysis. 


\section{a}

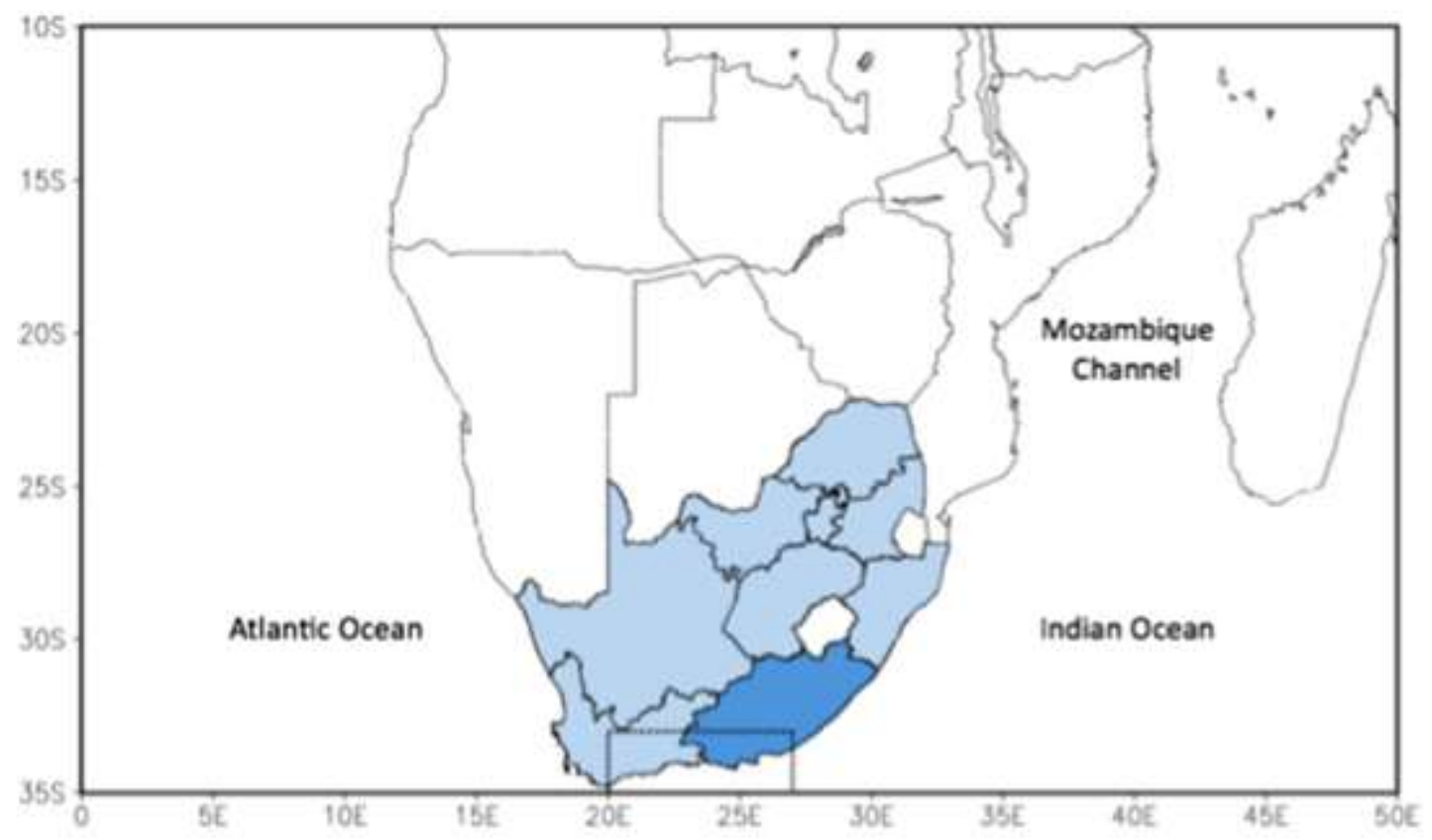

b

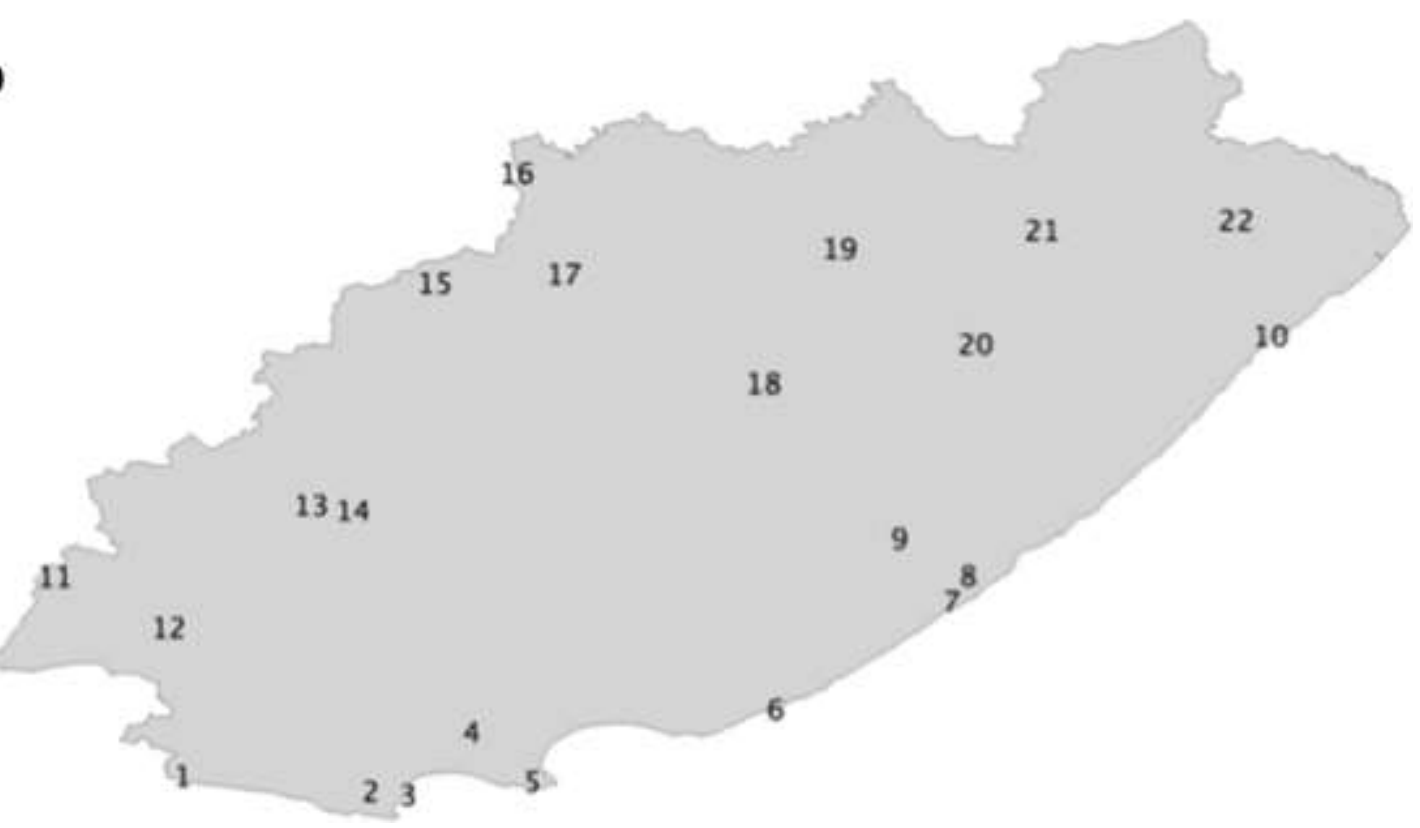

Fig. 1 The geographical location of South Africa is indicated by the lighter shade while the Eastern Cape is indicated by the darker shade (a). The all-year rainfall region is delineated by black dots (a). The Mozambique Channel and the Atlantic Ocean off the west coast of South Africa (a), are regions referred to in this paper. The location of the 22 daily rainfall stations used in this study (b). The stations are numbered and referred to accordingly in the paper

The NCEP reanalysis data, NCEP 1 (Kalnay et al. 1996), were utilized for the purpose of identifying and tracking COLs for the period 1979-2009. COLs over South Africa have a typical length scale of $1000 \mathrm{~km}$ (e.g. Singleton and Reason 2007) and are therefore resolved on the $2.5^{\circ}$ resolution grid of the NCEP data. A COL is defined as a local minimum in the geopotential height at the $500 \mathrm{hPa}$ pressure level, accompanied by a cold-core, similar to the criteria used by Favre et al. (2012). The daily average geopotential height of the $500 \mathrm{hPa}$ pressure level as well as the daily average temperature of the 500 hPa pressure level are utilized for identifying and tracking COLs. COLs existing for at least one day 
are considered in this study. COLs are identified and tracked by applying an objective, automated tracking algorithm. Geopotential minima are identified by considering each grid point in the domain and by determining whether this grid point represents a local geopotential minimum. This is achieved by comparing the geopotential of the grid point to that of the surrounding eight grid points, following Engelbrecht et al. 2013. Potential COL tracks are constructed by identifying the nearest geopotential minima of timestep $\mathrm{t}+1$ within a $1000 \mathrm{~km}$ from the geopotential minima at timestep t. This distance criterion limits COLs to move faster than $42 \mathrm{~km} / \mathrm{hr}$ (Favre et al. 2012). The tracking procedure is developed in such a manner that geopotential minima can only be employed in one track that is essentially one potential COL event. All these potential COL events are then subjected to a cold-core test. The approach utilized by Favre et al. (2012) is applied in this study. For each of the tracks, a temperature minimum need to be located within $600 \mathrm{~km}$ from the geopotential height minima that form part of a track. To accommodate hybrid systems, this temperature minimum distance criterion is adjusted in this study - a cold-core needs to be present more than half of the time-steps for a track to be classified as a COL track. From this COL dataset for the period 1979-2009, all the COLs that occurred within $700 \mathrm{~km}$ from the centroid of the Eastern Cape Province were considered to potentially be responsible for rainfall over the province. These COLs are referred to as 'Eastern Cape COLs' in the remainder of this paper.

Rainfall associated with COLs is typically widespread (Taljaard 1985; Taljaard 1996) while some COLs are accompanied by heavy rainfall (e.g. Estie 1981; Singleton and Reason 2006). In this study, COL events considered to contribute to rainfall are identified from the Eastern Cape COL events that occurred during 1979-2009. COL induced rainfall is defined as a COL day that is accompanied by the occurrence of rainfall at more than $30 \%$ of the stations, from here on referred to as 'COL rain days'. The COL days that did not satisfy the criteria are referred to as 'low impact COL days' in the remainder of this paper.

For each of the weather stations, the percentage of rainfall contributed by COL rain days relative to the total rainfall over the period 1979-2009 was determined. Further, with the Eastern Cape being climatically diverse, hosting part of the all-year rainfall region (Fig. 1a) while the larger part of this province is characterized by summer rainfall, the relative monthly contributions of COL rain days to the total monthly rainfall are determined.

The intensity of COL systems can be measured by the amount of rain per COL day (Risbey et al. 2012). The COL rain days identified is therefore perfectly suited for this analysis. For each of the COL rain days, the average rainfall is determined and categorized into small ( $0<$ average rain $<10 \mathrm{~mm}$ ), medium ( $10 \leq$ average rain $<20 \mathrm{~mm}$ ) and large events (average rain $\geq 20 \mathrm{~mm}$ ). These rainfall categories were chosen after consultation with a South African rainfall specialist (personnel communication, L Dyson). The geopotential height and temperature minima of the $500 \mathrm{hPa}$ pressure level as well as the average rainfall distributions for each of the COL days intensity categories are presented. To gain 
insight into the atmospheric circulation associated with each of the intensity categories, composite maps based on NCEP reanalysis data are derived from the $500 \mathrm{hPa}$ and $850 \mathrm{hPa}$ geopotential heights.

\section{RESULTS AND DISCUSSION}

\section{Frequency of cut-off lows}

During the period 1979-2009, a total of 85 Eastern Cape COLs occurred. Of these, 63 COL events that spanned over 96 days were associated with rainfall reported at more than $30 \%$ of the weather stations.

a

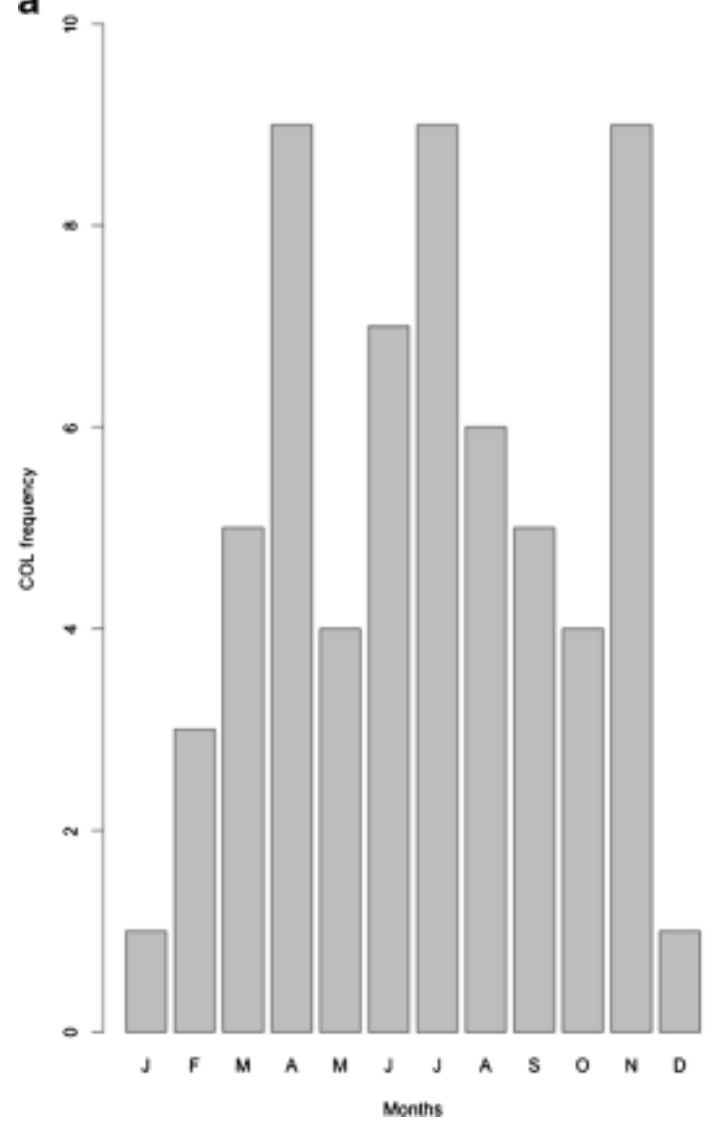

b

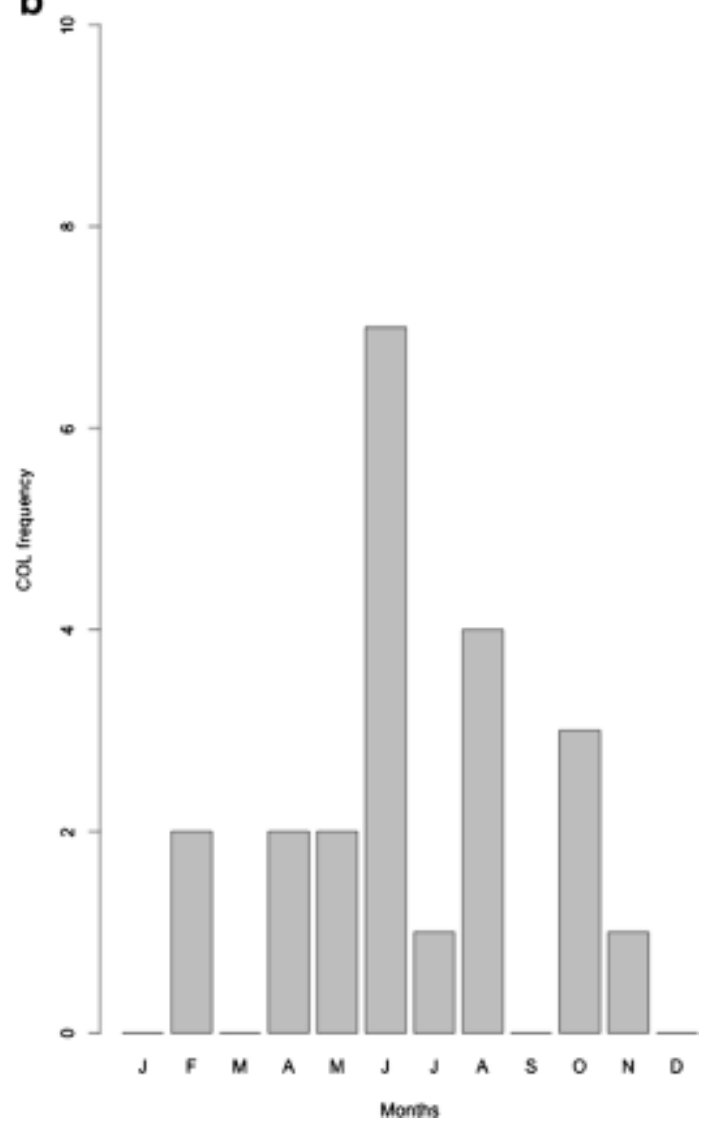

Fig. 2 Monthly frequency of COL events that are within $700 \mathrm{~km}$ from the centroid of the Eastern Cape during the period 1979 to 2009 for (a) COL rain events (more that $30 \%$ of weather stations report rainfall on these COL days) and (b) low impact COL events (30\% and less of the weather stations report rainfall on these COL days)

The remaining $22 \mathrm{COL}$ events spanned over 32 days and were associated with rainfall with a distribution of $30 \%$ and less, qualifying these 22 (32) COL events (days) as low impact COL events (days). The monthly frequency of COLs during the study period, 1979-2009, can be seen in Fig. 2(a) and (b) for COL rain day events (63 events) and low impact COL events (22 events) respectively. April, July and November are the months with the highest occurrence of COL rain day events (Fig. 2a). Less than $20 \%$ of COL events during April, July and November are low impact COL events (Fig. 2b). June and August also stand out as favourable months for COLs to occur, but $50 \%$ and $40 \%$ of COLs during June and August qualify as low impact COL events respectively. March and September are characterized by being all COL rain events while $40 \%$ of February and October COL events are low impact COL events. January and December are clearly the months most unfavourable for the 
occurrence of COLs, but the COLs that did occur during these summer months were both COL rain events. The COL event that occurred in January is the famous Laingsburg flood event (Estie 1981). The vast area that can be affected by COLs is illustrated by this COL event. Even though the largest impact occurred over the western parts of South Africa, the Eastern Cape still experienced rainfall at 18 of the 22 weather stations $(81 \%)$ employed in this study.

a

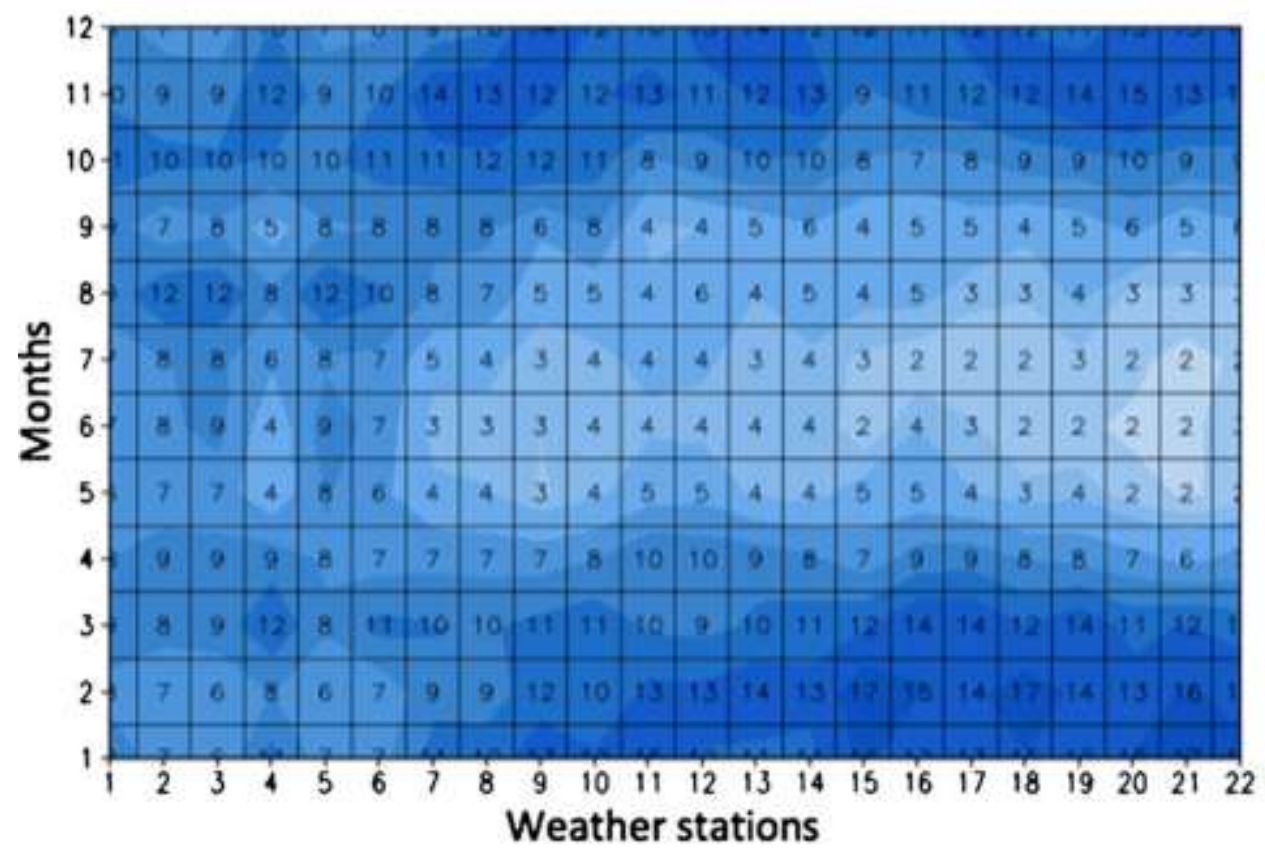

b

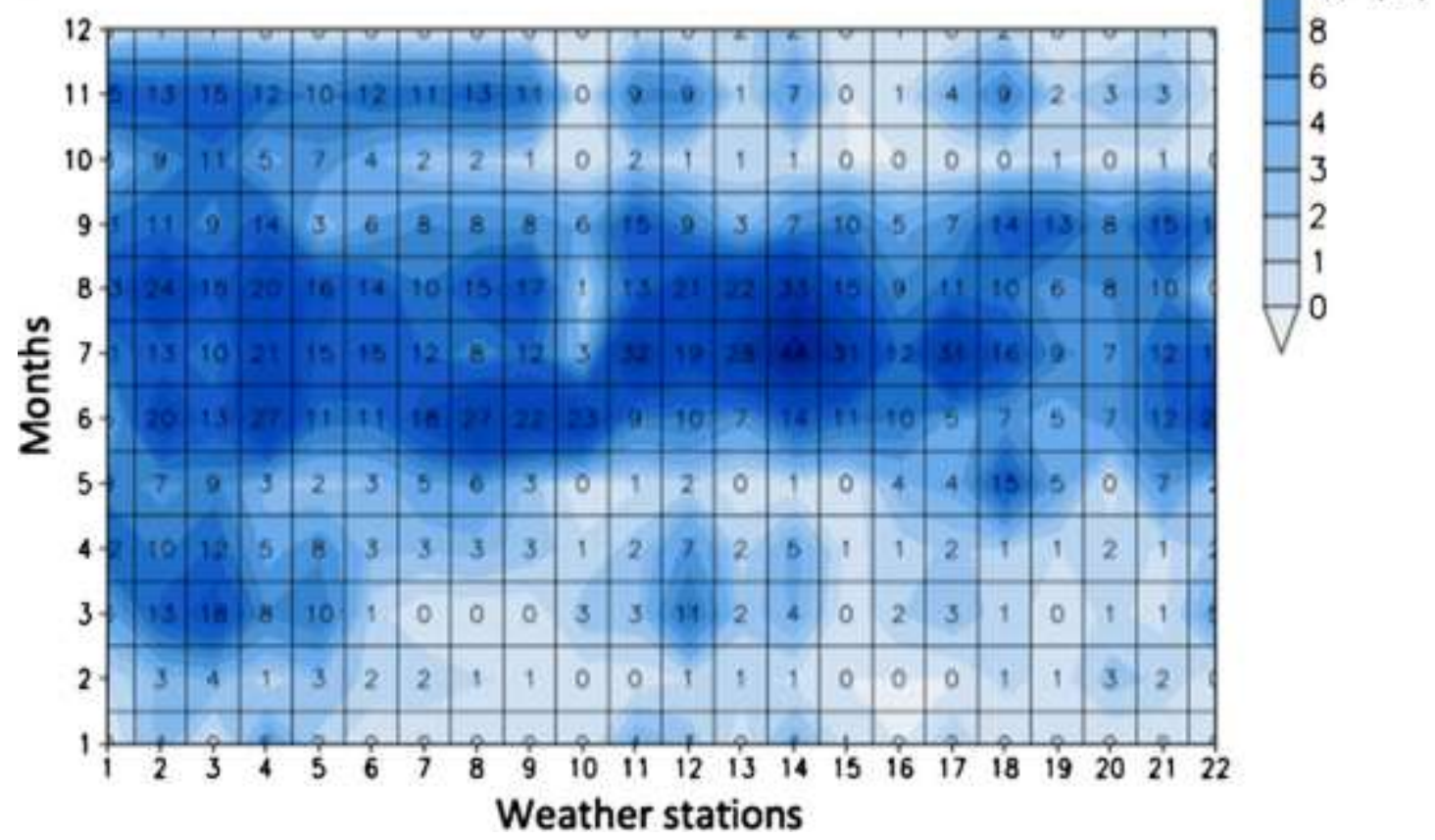

Fig. 3 The percentage of the annual rainfall during January to December at the 22 weather stations (a) and the percentage of $\mathrm{COL}$ associated rainfall from the total monthly rainfall (b) 
The seasonal frequencies of both COL rain events and low impact COL events found within $700 \mathrm{~km}$ from the centroid of the Eastern Cape Province, have a winter maximum and a summer minimum. The seasonal frequency of COLs over South Africa has an autumn maximum and summer minimum for the period 1973-2002 (Singleton and Reason 2007). Interesting to note is that for the sub-period 19831992, a winter maximum and summer minimum occurred (Singleton and Reason 2007).

\section{Contribution of cut-off lows to rainfall}

The average monthly and annual contribution of COL induced rainfall (rainfall on COL rain days) to the total monthly and annual rainfall totals is determined at each weather station for the period 19792009. The monthly contribution of COL induced rainfall is expressed as the percentage contribution by COLs to the percentage of the annual rainfall for each of the months. The relative importance of the contribution of COL induced rainfall to rainfall in general is captured by this representation.

The average monthly percentage contribution to the annual rainfall for the period 1979-2009 can be seen in Fig. 3a. On the x-axis, the 22 weather stations are displayed while the corresponding monthly values are displayed on the y-axis. Stations 1-6 experience all-year rainfall, while stations 7-22 clearly receive the bulk of their rainfall during summer (Fig. 3a). The stations in the all-year rainfall region have rainfall peaks during March/April, August and October/November (Fig. 3a).

Over the all-year rainfall region, the largest contribution of COLs to rainfall occurs at similar times as the three rainfall peaks observed in the annual total rainfall distribution (Fig. 3b). During March/April, stations 1-5 receive in general in the order of $10 \%$ of this rainfall associated with COLs. Station 6 falls in the all-year rainfall region as well, but does not experience a March/April maximum in the contribution of COLs to the monthly rainfall (Fig. 3b). This can most likely be explained by the relative contribution of tropical-temperate troughs to rainfall being more important at Station 6 as tropical-temperate troughs have a higher frequency in the Station 6 region during March compared to the region west of it (Hart et al. 2012). August is the month over the all-year rainfall region when the largest contribution by COLs to the total monthly rainfall is in general experienced. During November, the contribution by COLs to the total monthly rainfall for the stations within the all-year rainfall region is as during March, also in the order of $10 \%$. Interesting to note is that during November, this relative maximum contribution of COL induced rainfall to the monthly total rainfall, extends to Station 7 (Fig. 3b) and its immediate surroundings. It may be noted that climatologically, November is the month with the highest frequency of tropical-temperate troughs (Hart et al. 2012) that is very likely to interact with the COLs, which also experience relatively high frequencies during November (Fig. 2). Interesting to note, is the relative high contribution by COLs to rainfall during June, July and August at Station 4. During June $26 \%$ of the rainfall is associated with COLs (Fig. 3b). The relative high contribution by COLs to rainfall during June is partly the result of June being in general one of the driest months at Station 4. Good falls of rain associated with a single COL event can therefore have a notable impact on the contribution by COLs to rainfall during June. For example, the COL rain days of 23 June 1985 and 12 June 1993 contributes to 7\% of the June rainfall respectively while the COL event of 11 June 1997 to 12 June 1997 contributes to $8 \%$ of the June rainfall. These 4 COL rain days, contribute in total to 
$22 \%$ of the rainfall during June at Station 4. The relative high contribution by COLs to rainfall at Station 4 during July and August (Fig. 3b) can be attributed to the COL events of 20 July 1979 to 21 July 1979 (Fig. 4a) and 1 August 2006 to 3 August 2006 respectively (Fig. 4b). These COL events, contributed each to $9 \%$ of the rainfall during July and August at Station 4.

a

July

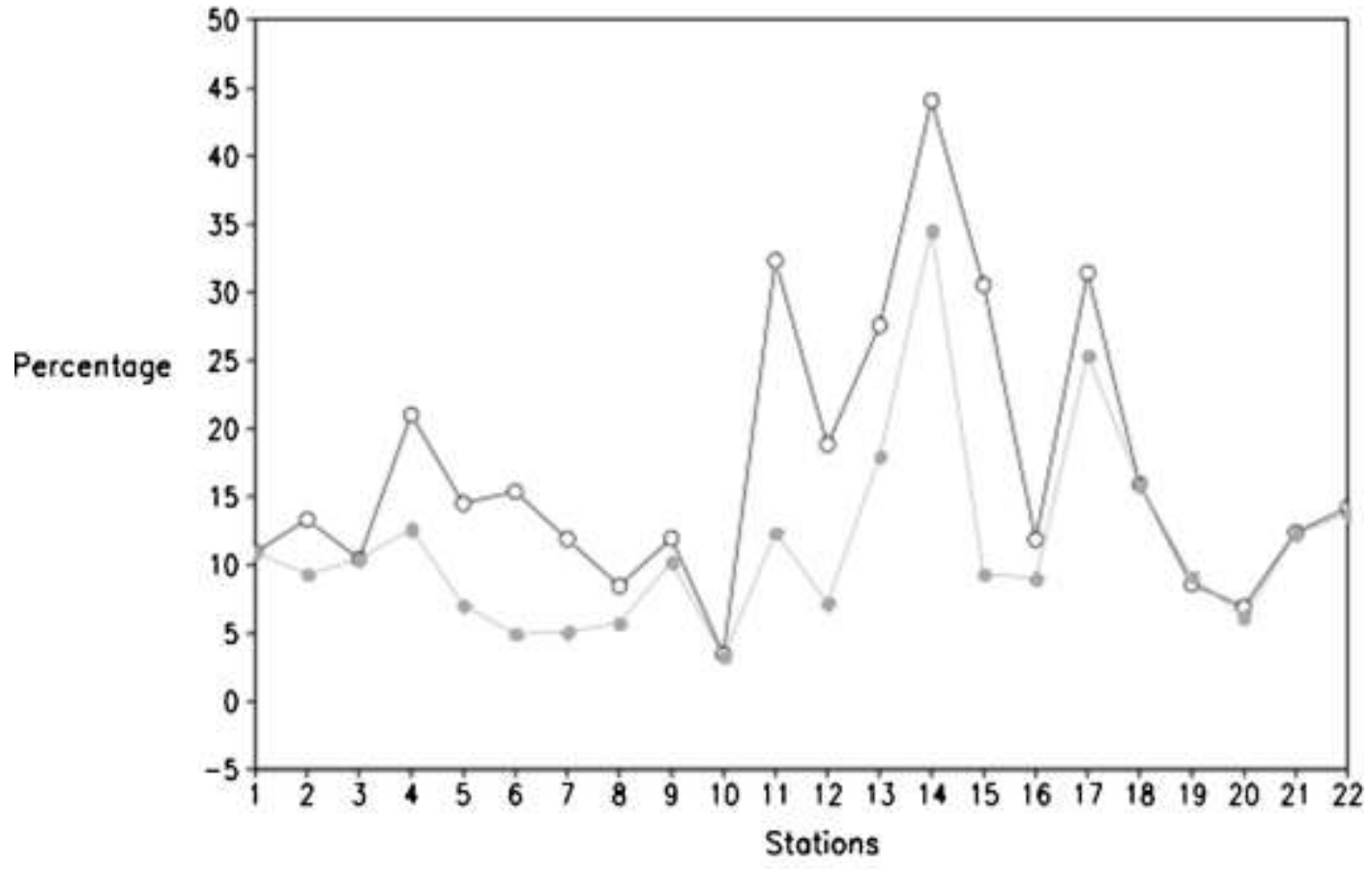

b

August

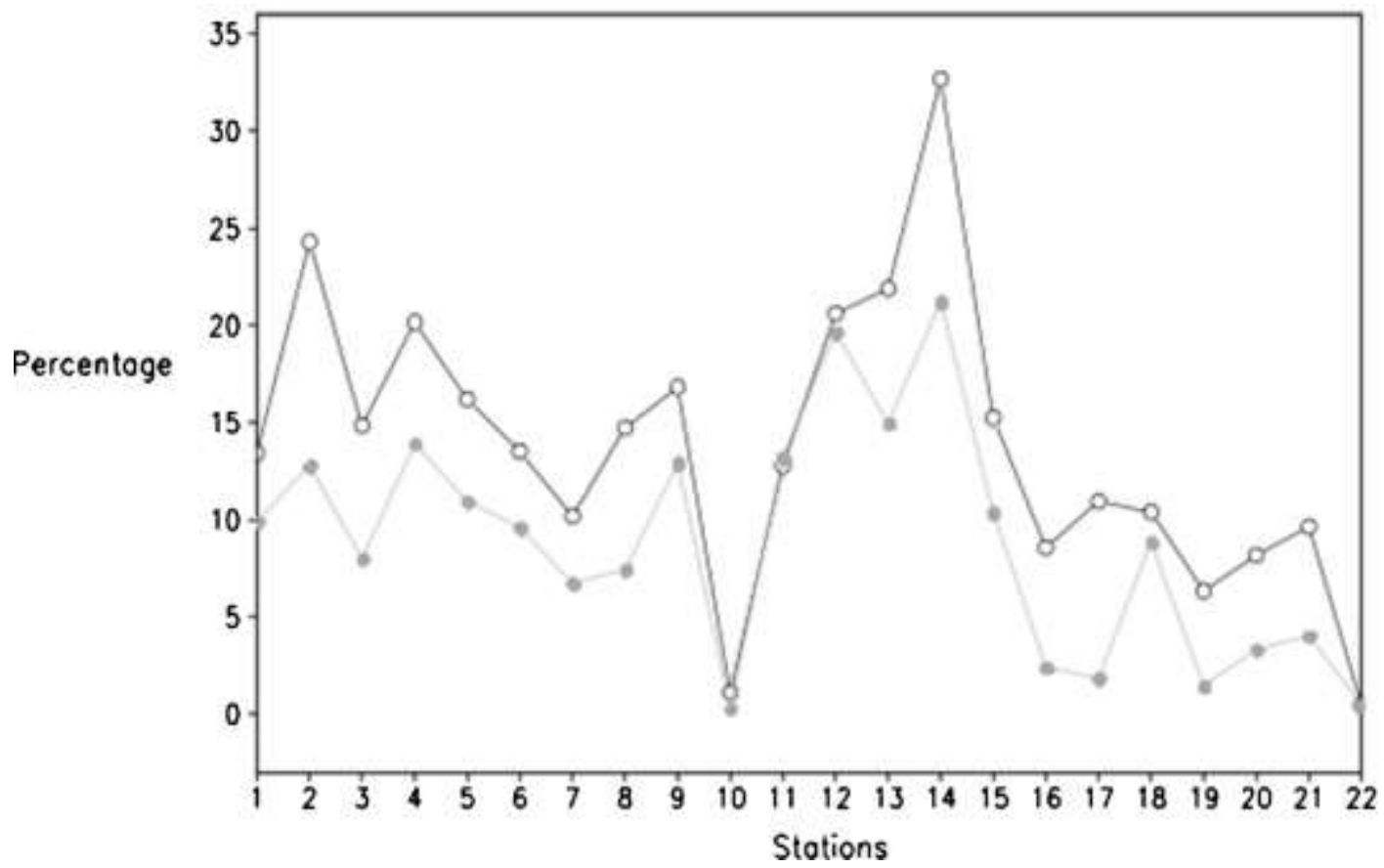

Fig. 4 The percentage contribution of rainfall associated with COLs to the total monthly rainfall at each of the 22 weather stations for July (a) and August (b) is indicated by the black line. The grey line represents the percentage contribution of rainfall associated with COLs to the total monthly rainfall at each of the 22 weather stations where the events of 20-21 July 1979 and 1-3 August 2006 are excluded for July (a) and August (b) 
Contrary to the all-year rainfall region where the largest contribution of COLs to monthly rainfall totals coincide with the annual rainfall peaks, the stations over the summer rainfall region experience in general the largest contribution to monthly rainfall by COLs during the winter months (Fig. 3b). During July, it can be seen that the contribution by COLs to the total monthly rainfall is strikingly higher at the stations over the northwestern part of the Eastern Cape and to a lesser extent along the adjacent coastal regions, compared to the remainder of the province (Fig. 4a). This larger contribution can be attributed to a single COL event on 20-21 July 1979. The COL event of 1-3 August 2006 had a similar effect on the contribution to the total monthly rainfall for stations located mostly over the western part of the Eastern Cape (Fig. 4b).

Considering the contribution of COL induced rainfall to annual rainfall totals, the largest contribution by COLs occurs southwards of the main escarpment, with the maximum contribution confined to the coast and adjacent interior from Port Elizabeth westwards (Fig. 5). Here, the contribution by COLs to annual rainfall totals reaches $12 \%$ at Station 2. From the coast, a gradual decrease is found northwards over the interior, with the contribution of COL induced rainfall to annual rainfall totals being 2-3\% over the far northern parts of the Eastern Cape.

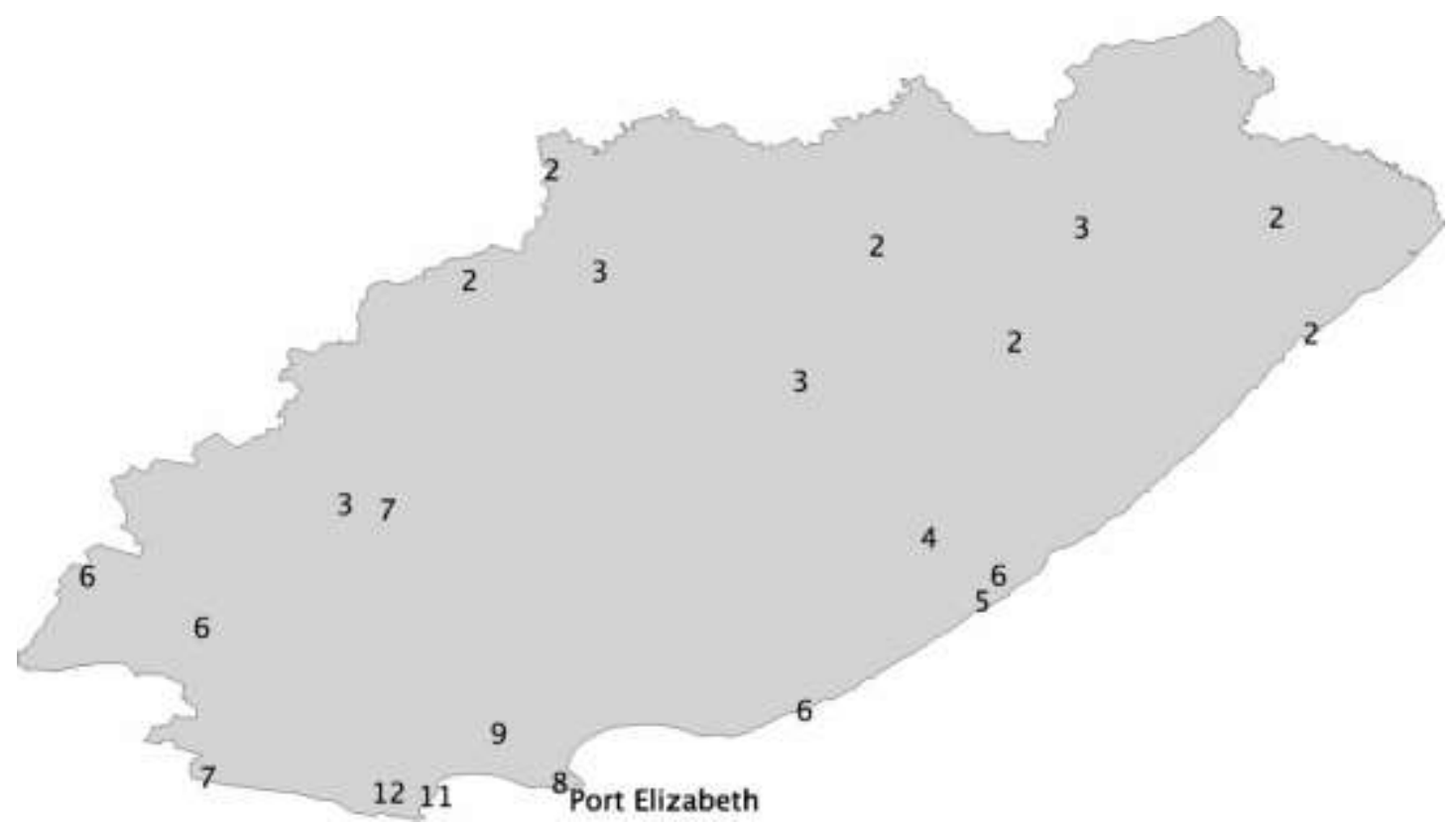

Fig. 5 The percentage contribution to the annual rainfall by COLs within $700 \mathrm{~km}$ from the Eastern Cape centroid and with rainfall reported at more than $30 \%$ of the weather stations

\section{Cut-off low intensity}

All 96 days of the $63 \mathrm{COL}$ rain events are divided into the rainfall categories small ( $0<$ average rain<10 $\mathrm{mm}$ ), medium $(10 \leq$ average rain $<20 \mathrm{~mm}$ ) and large (average rain $\geq 20 \mathrm{~mm}$ ) rain days. The small rainfall day category is composed of $53 \%$ of all COL rain days. Of these, the majority of rain days occur during autumn and winter (Fig. 6b). In the medium rainfall day category, 25\% of COL rain days occur, with most of these days occurring during winter and spring (Fig. 6e). COL rain days responsible for large rain day events occur on $22 \%$ of the COL rain days. The distribution of large rain day events is uniform through the year, but with slight peaks during winter (Fig. 6h). From Fig. 6 (b,h), it can be 
seen that all but $1 \mathrm{COL}$ rain day during April is found within the small rainfall day category - this translates to $90 \%$ of the cut-off low rain days during April being small rainfall events.
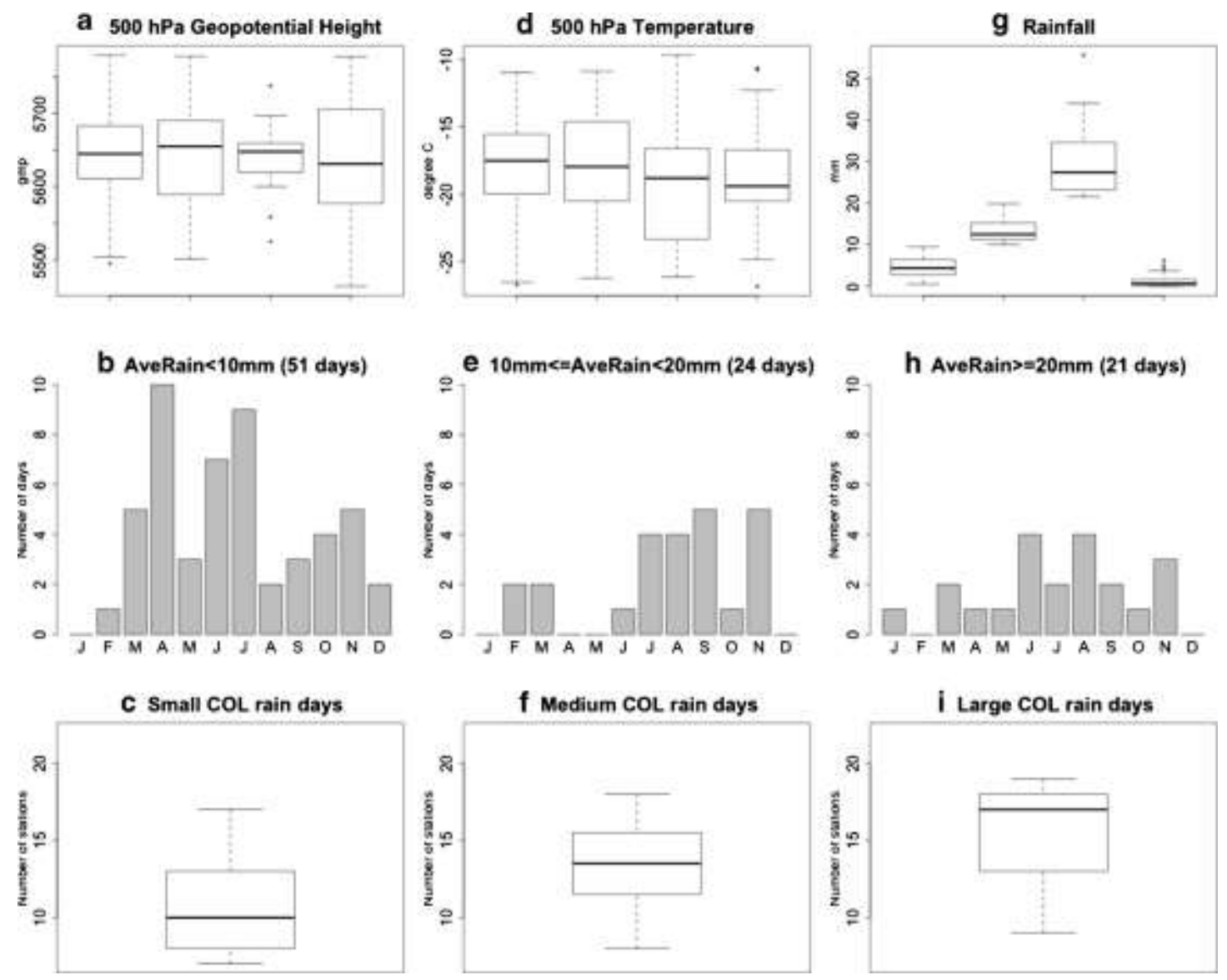

Fig. 6 The distribution of the $500 \mathrm{hPa}$ height (a), the $500 \mathrm{hPa}$ temperature (d) and the rainfall (g) of the COL days for the small (first boxplot), medium (second boxplot) and large (third) rainfall categories. The fourth boxplot in a, $\mathrm{d}$ and $\mathrm{g}$ represents the distribution of the $500 \mathrm{hPa}$ height, the $500 \mathrm{hPa}$ temperature and the rainfall associated with low impact COL days respectively. The monthly frequency of COL rain days for the small rainfall category (b), the medium rainfall category (e) and the large rainfall category (h). The number of stations that reported rainfall for $\mathrm{COL}$ days in the small rainfall category (c), the medium rainfall category (f) and the large rainfall category (i)

The daily rainfall distribution within the small, medium and large rainfall categories is shown in Fig. 6 (g). The first, second and third boxplot represents the small, medium and large rainfall categories respectively. The fourth boxplot represents the COL days that occurred over the study region that did not comply to the criteria where the number of stations that report rainfall need to exceed $30 \%$ (refer to Fig. 2b). For the greater and equal to $20 \mathrm{~mm}$ events (Fig. 6g, boxplot 3), a COL rain day with a spatial average of more than $50 \mathrm{~mm}$ has been recorded. The fourth boxplot on Fig. 6 (g) shows that the COL days that are associated with $30 \%$ and less of the stations reporting rainfall, are all days within the small rain day category. From Fig. 6 (c,f,i), it can further be seen that there is an association between the rain day category and the number of stations that reported rainfall - the median increase from the small rainfall category to the large rainfall category. Large rain day events are mostly also days of widespread rainfall (Fig. 6i). There are three exceptions, when 9 to 10 stations reported rainfall (indicated by the lower whisker on Fig. 6i). On these COL rain days, rainfall occurred along most of 
the coast and on one of these days also over the adjacent interior. The spatial distribution of rainfall for each of the COL rain day categories can be seen in Fig. 7. No preferred area of rainfall is distinguishable for small COL rain days (Fig. 7a). For medium COL rain days (Fig. 7b), the rainfall distribution has a maximum over the northeastern part of the Eastern Cape extending to the coast as well as along the extreme western part of the coast. A very prominent feature of large COL rain days is the south-north gradient in rainfall with heavy falls of rain along most of the coast (Fig. 7c).

a
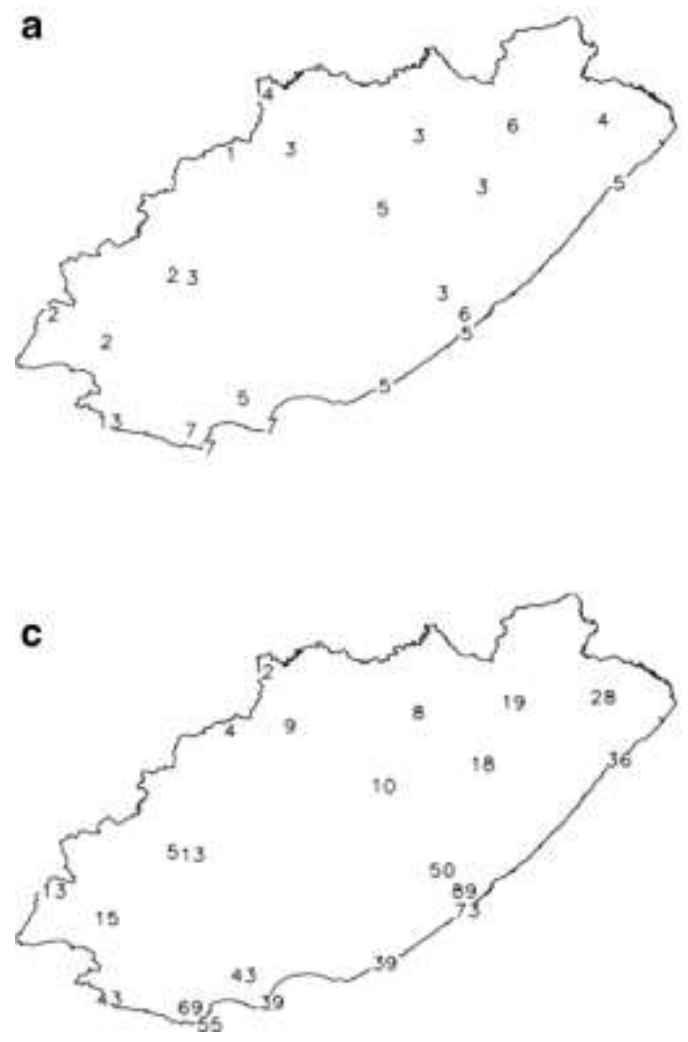

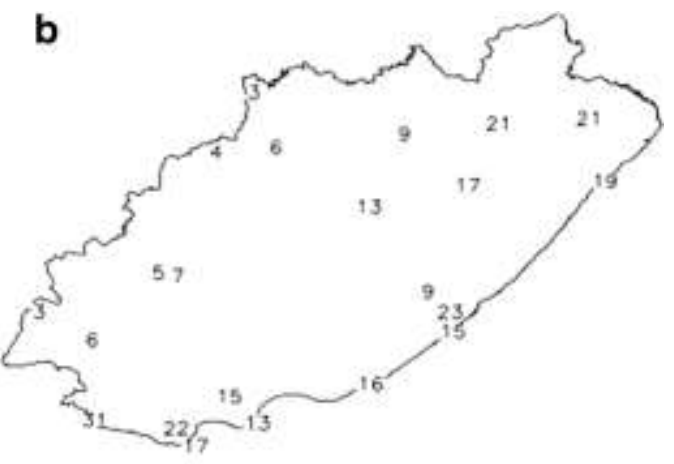

Fig. 7 Spatial distribution of rainfall for the small (a), medium (b) and large (c) COL rain day categories

Fig. 6 (a) shows the depth of the COL centres on the $500 \mathrm{hPa}$ pressure level for the various rain day categories (small to large, first to third boxplot respectively) as well as for low impact COL days (30\% and less of the stations report rainfall) (Fig. 6a, fourth boxplot). It can be seen from Fig. 6 that the median values for small to large rain day categories are very similar at about $5650 \mathrm{gpm}$. The range of the depth of the COL centres for the small and medium rain day categories is also comparable, ranging between $5495 \mathrm{gpm}$ and $5780 \mathrm{gpm}$ (Fig. 6a). The difference between the small and medium rain day categories is the slightly larger range of COL centre depths between the $25^{\text {th }}$ and $75^{\text {th }}$ percentiles, with the medium rain days having the larger range. In the large rain day category, the range of the depth of the COL centres is, with the exception of three outliers, much smaller compared to the other rain day categories (Fig. 6a). Low impact COL days have the largest range of the depth of the COL centres (Fig. 6a, fourth boxplot). The temperature of the COL centres for the small to large rain day categories exhibit very similar characteristics (Fig. 6d, first to third boxplot). The median values are of a similar magnitude although a slight decrease is seen from the small rain day to the large rain day events. The range of the COL centre temperature for the different rain day categories is also very similar, ranging 
from -11 to $-26.7,-10.9$ to -24.2 and -9.7 to -26.1 for the small, medium and large rain day categories respectively (Fig. 6d). Although the range and the median value of the COL centre temperature for the different rainfall categories are very similar, the $25^{\text {th }}$ to $75^{\text {th }}$ percentile range of the large rain day category is larger than for the other rain day categories. Noteworthy is that the depth and temperature of the $500 \mathrm{hPa}$ COL centres associated with low impact COLs (Fig. 6a and 6d, fourth boxplot) exhibit ranges comparable to that of the COLs associated with rain.

\section{Atmospheric circulation attributes of COL rain days}

Composite maps of the $500 \mathrm{hPa}$ and $850 \mathrm{hPa}$ heights for each of the COL rain day categories as well as for low impact COL days can be seen in Fig. 8 (a-c) and Fig. 8 (d) respectively. The positions of the $500 \mathrm{hPa}$ COL centres for the small, medium and large COL rain day categories are shown in Fig. 8 (eg) while the COL centres of the low impact COL days are shown in Fig. 8 (h). The 500 hPa pressure level composite maps of the small, medium and large COL rain day categories are in general very similar with regard to the orientation of the trough as indicated by the shaded contours in Fig. 8 (a-c). This applies to the geographical position of the COL centres (Fig. 8 (e-g)) as well. The depth of the COL centres as represented by the composite maps is also of comparable magnitude. The depth of the low impact COL days is similar to that of the COL rain day categories. However, the geographical position of the COL centres, as revealed by the $500 \mathrm{hPa}$ pressure level composite map (Fig. 8d), is located further southwards than for the COL rain day categories. From Fig. 8 (h), it can be seen that the overall location of low impact COL centres is, apart from a higher frequency further southwards, very similar to the COL rain day centres.

Contrary to the atmospheric circulation characteristics on the $500 \mathrm{hPa}$ pressure level that seem to be very similar for the various COL rain day categories, the atmospheric circulation on the $850 \mathrm{hPa}$ pressure level for the various COL rain day categories reveals dissimilarities with regards to the position of the $850 \mathrm{hPa}$ low/trough (solid contours in Fig. 8 (a-c)). For the small COL rain day category, the $850 \mathrm{hPa}$ low is located just off the coast in the Port Elizabeth area, a position not very favourable for low-level flow impinging on the coast (Fig. 8a). The $850 \mathrm{hPa}$ circulation associated with the medium COL rain day category is characterized by the trough being located over the central to eastern part of the Eastern Cape, extending northwestwards to Botswana and southeastwards over the ocean (Fig. 8b). The position of the trough is conducive to aid in rainfall formation over the northeastern part of the Eastern Cape and to contribute to onshore flow along the extreme western part of the Eastern Cape coast, consistent with the regions of maximum rainfall for this specific rainfall category (Fig. 7b). The $850 \mathrm{hPa}$ low associated with the large COL rain day category (Fig. 8c) is located over the eastern part of the Eastern Cape and extends over the ocean with its recurving flow onshore along the coast west of Station 10. Low impact COL days are characterized by the $850 \mathrm{hPa}$ low located to the south of the country, inducing low-level flow not favourable for rainfall formation (Fig. 8d). 
a
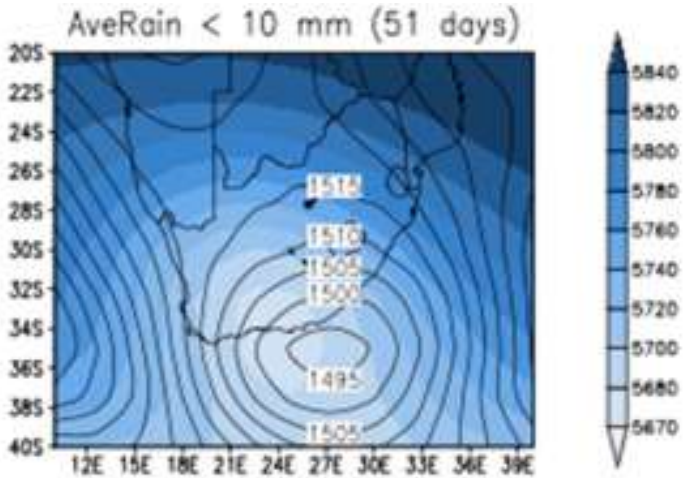

b
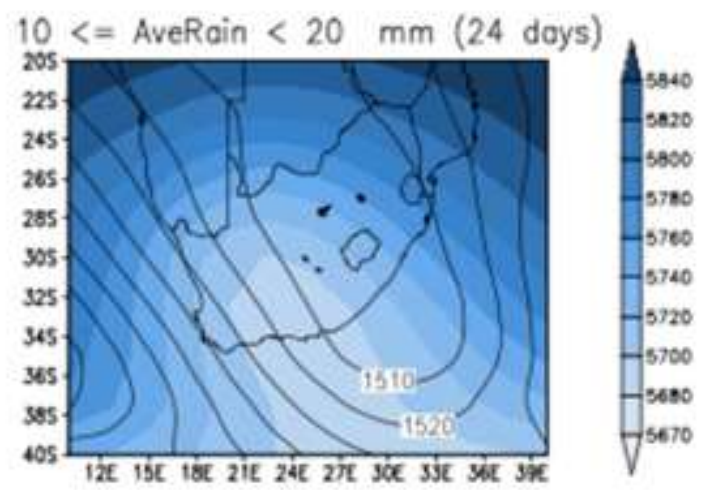

C
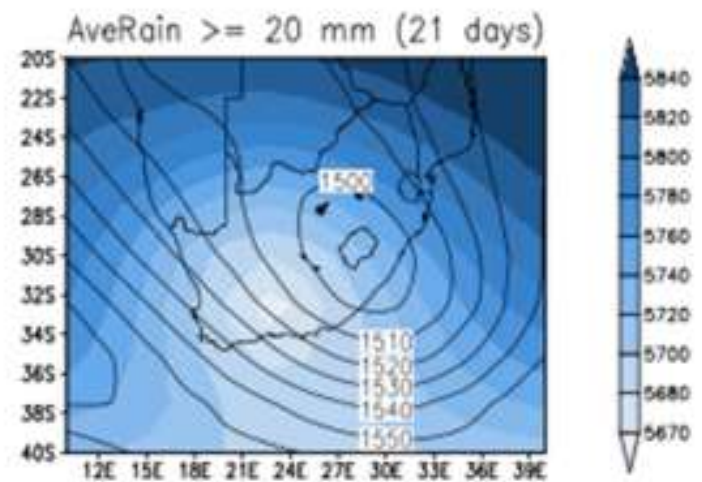

d

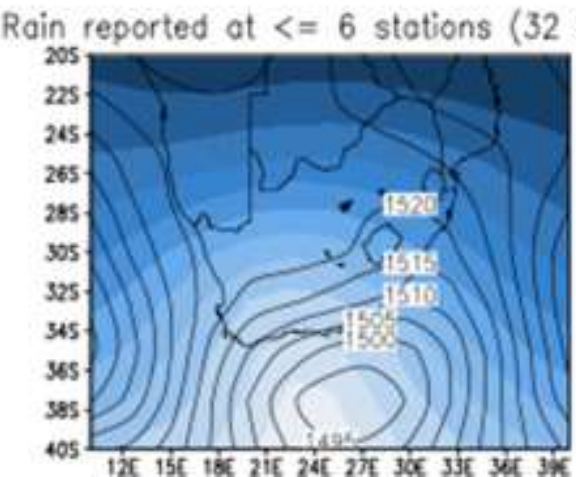

e

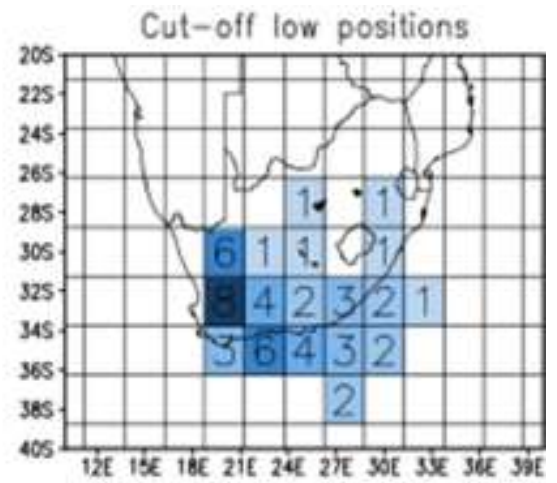

f

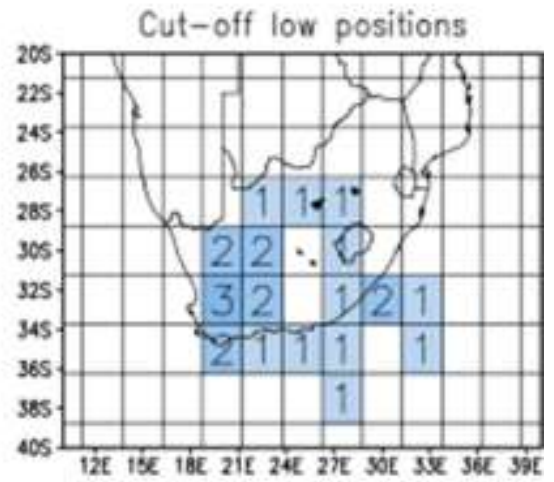

g

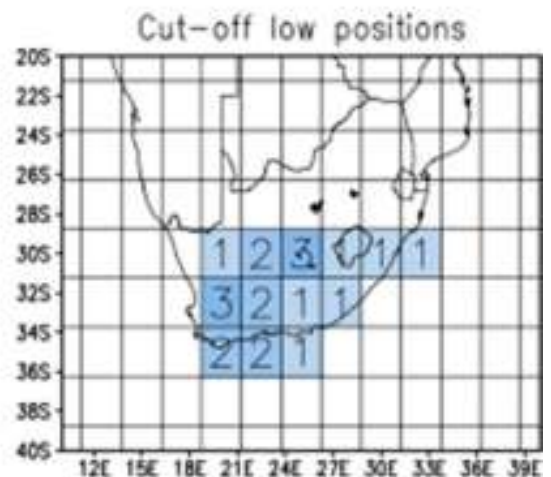

h

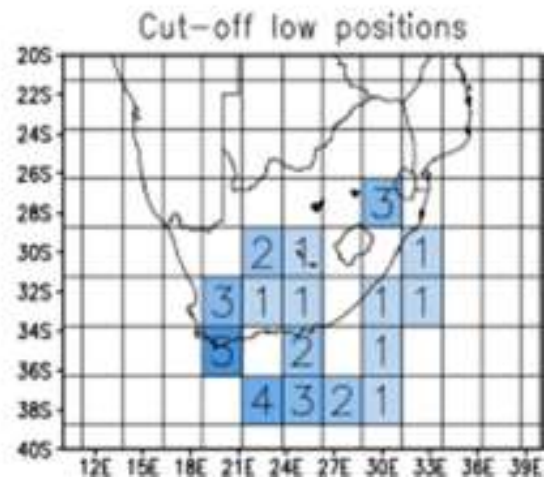

Fig. 8 Composite maps of the $500 \mathrm{hPa}$ (shaded) and $850 \mathrm{hPa}$ (contour) heights for COL rain days of the small (a), medium (b) and large (c) rain day categories as well as for low impact COL days (d). Frequency of the $500 \mathrm{hPa}$ COL centres for the small (e), medium (f) and large (g) rain day categories as well as for low impact COL days (h) 


\section{CONCLUSIONS}

In this study, 31 years of daily NCEP reanalysis data of the $500 \mathrm{hPa}$ geopotential heights and temperature for the period 1979-2009 were utilized to objectively identify and track COLs with durations of at least 1 day. During the period 1979-2009, a total of 85 COLs occurred within $700 \mathrm{~km}$ from the centroid of the Eastern Cape. COLs satisfying this distance criterion can potentially contribute to rainfall over the Eastern Cape. Daily rainfall data from 22 weather stations for the period 1979-2009 were utilized for the rainfall analysis. Considering all COLs that occurred within $700 \mathrm{~km}$ from the centroid of the Eastern Cape, 63 of these COLs (74\%) are associated with a rainfall distribution of more than $30 \%$. The seasonal frequency of COL events associated with a rainfall distribution of more than $30 \%$ has a winter maximum and a summer minimum. This seasonal frequency distribution also applies to COL events with a rainfall distribution of $30 \%$ and less (including no rainfall events). Fiftythree percent of the rain days of the COL events with a rainfall distribution of more than $30 \%$ had average rainfall of greater than zero and less than $10 \mathrm{~mm}$ while $25 \%$ of the rain days had average rainfall equal to or greater than $10 \mathrm{~mm}$ and less than $20 \mathrm{~mm}$ with the other $22 \%$ having average rainfall equal to or greater than $20 \mathrm{~mm}$. COL rain days with average rainfall greater than zero and less than 10 $\mathrm{mm}$ occur most frequently during autumn and winter. Winter and spring are the seasons with the highest occurrence of COL rain days when average rainfall is equal to or greater than $10 \mathrm{~mm}$ and less than $20 \mathrm{~mm}$. COL rain days with average rainfall equal to or greater than $20 \mathrm{~mm}$ have a uniform distribution, but with slight peaks during the winter months. The contribution of COL induced rainfall to the annual rainfall is largest along the coast and adjacent interior of the all-year rainfall region part of the Eastern Cape, with the maximum contribution reaching 12\%. Over the summer rainfall region the contribution of COL induced rainfall is much less. Considering the contribution of COL induced rainfall to monthly rainfall totals, the summer rainfall region of the Eastern Cape receives the largest contribution to monthly rainfall totals during the winter months. Individual extreme COL events have an impact on their contribution to rainfall on a monthly time-scale. Heavy widespread rainfall associated with COLs exhibits a strong south-north gradient in the amount of rainfall, with the maximum rainfall along the western part of the Eastern Cape coast. There seems to be in general a relationship between the magnitudes of COL induced rainfall and the number of stations that report rainfall - with higher average rainfall, an increase in the number of stations reporting rainfall is observed.

The results of this study suggest that the low-level circulation, in particular the position of the surface low, seems to be the determining factor with regard to the distribution and amount of COL induced rainfall over the Eastern Cape. With rainfall being used as a measure of COL intensity, the $500 \mathrm{hPa}$ circulation was very similar for three rainfall categories, while the surface circulation had distinctly different characteristics with regard to the position of the low/trough. This suggests that for further potential improvement in forecasting COL rainfall, a better understanding and simulation of the lowlevel circulation and processes, in particular the role of the topography in these processes, are needed. 


\section{Acknowledgements}

Sam Molekwa would like to thank the Agricultural Research Council (ARC) for funding his MSc studies. The contributions by Dr Fyfield, Dr Tsubo and Dr Moeletsi from the ARC - Institute for Soil, Climate and Water (ISCW) are appreciated. Thank you to the SAWS, in particular Mrs Dawn Mahlobo, for providing rainfall data of the Eastern Cape.

\section{References}

Dyson LL, van Heerden J (2002) A model for the identification of tropical weather systems over South Africa. Water SA 28:249-258

Engelbrecht CJ, Engelbrecht FA, Dyson LL (2013) High-resolution model-projected changes in mid-tropospheric closed-lows and extreme rainfall events over southern Africa. Int J Climatol 33:173-187. doi: 10.1002/joc.3420

Estie KE (1981) The Laingsburg flood disaster of January 1981. South African Weather Bureau Newsletter $383: 19-32$

Favre A, Hewitson B, Lennard C, Cerezo-Mota R, Tadross M (2011) Cut-off Lows in the South Africa region and their contribution to precipitation. Climate Dyn 38:1473-1487

Favre A, Hewitson B, Tadross M, Lennard C, Cerezo-Mota R (2012) Relationships between cut-off lows and the semi-annual and southern oscillations. Climate Dyn 38(7):1473-1487. doi: 10.1007/s00382-011-1030-4

Hart NCG, Reason CJC, Fauchereau N (2012) Cloud bands over southern Africa: seasonality, contribution to rainfall variability and modulation by the MJO. Climate Dyn. doi: 10.1007/s00382-012-1589-4

Jury MR, Levey K (1993) The climatology and characteristics of drought in the eastern Cape of South Africa. Int J Climatol 13:629-641

Kalnay E, Kanamitsu M, Kistler R, Collins W, Deaven D, Gandin L, Iredell M, Saha S, White G, Woollen J, Zhu Y, Chelliah M, Ebisuzaki W, Higgens W, Janowiak J, Mo KC, Ropelewski C, Wang J, Leetmaa A, Reynolds R, Jenne R, Joseph D (1996) The NCEP/NCAR 40-year reanalysis project. Bull Amer Meteor Soc 77:437-472

Keable M, Simmonds I, Keay K (2002) Distribution and temporal variability of $500 \mathrm{hPa}$ cyclone characteristics in the southern hemisphere. Int J Climatol 22:131-150

Lindesay JA, Jury MR (1991) Atmospheric circulation controls and characteristics of a flood event in central South Africa. Int J Climatol 11:609-627

Malherbe J, Engelbrecht FA, Landman WA, Engelbrecht CJ (2012) Tropical systems from the southwest Indian Ocean making landfall over the Limpopo Basin, South Africa: a historical perspective. Int J Climatol 32:10181032. doi: $10.1002 /$ joc. 2320

Mason SJ, Jury MR (1997) Climatic variability and change over southern Africa: a reflection on underlying processes. Progress in Physical Geography 21:23-50 
Muller A, Reason CJC, Fauchereau N (2008) Extreme rainfall in the Namib Desert during late summer 2006 and influences of regional ocean variability. Int J Climatol 28:1061-1070

Risbey JS, McIntosh PC, Pook MJ (2012) Synoptic components of rainfall variability and trends in southeast Australia. Int J Climatol. doi: 10.1002/joc.3597

Singleton AT, Reason CJC (2006) Numerical simulations of a severe rainfall event over the Eastern Cape coast of South Africa: sensitivity to sea surface temperature and topography. Tellus 58A:355-367

Singleton AT, Reason CJ (2007) Variability in the characteristics of cut-off low pressure systems over subtropical southern Africa. Int J Climatol 27: 295-310

Taljaard JJ (1985) Cut-off lows in the South African region. South African Weather Bureau Technical Paper No $14,153 \mathrm{pp}$

Taljaard JJ (1995) Atmospheric circulation systems, synoptic climatology and weather phenomena of South Africa. Part 2. Atmospheric circulation systems in the South African region. Technical Paper No 28, SA Weather Bureau, Department of Transport, Pretoria

Taljaard JJ (1996) Atmospheric Circulation Systems, Synoptic Climatology and Weather Phenomena of South Africa. Part 6: Rainfall in South Africa. South African Weather Bureau Technical Paper No 32: 98 pp

Tennant W (2004) Considerations when using pre-1979 NCEP/NCAR reanalysis in the southern hemisphere. Geophysical Research Letters 31: L11112. doi: 10.1029/2004GL019751

Tennant WJ, Reason CJC (2005) Associations between the Global Energy Cycle and Regional Rainfall in South Africa and Southwest Australia. J Climate 18:3032-3047

Weldon D, Reason CJC (2013) Variability of rainfall characteristics over the South Coast region of South Africa. Theor Appl Climatol doi: 10.1007/s00704-013-0882-4 